Pesq. Vet. Bras. 37(7):725-728, julho 2017

DOI: $10.1590 / \mathrm{S} 0100-736 \mathrm{X} 2017000700012$

\title{
Tuberculose em felinos domésticos (Felis catus) no sul do Rio Grande do Sul ${ }^{1}$
}

\author{
Daniel M. Alves ${ }^{2}$, Sara P. da Motta², Rosimeri Zamboni², Clairton Marcolongo-Pereira ${ }^{3 *}$, \\ Josiane Bonel ${ }^{2}$, Margarida Buss Raffi ${ }^{4}$, Ana Lucia Schild ${ }^{4}$ e Eliza Simone V. Sallis ${ }^{4}$
}

\begin{abstract}
Alves D.M., Motta S.P., Zamboni R., Marcolongo-Pereira C., Bonel J., Raffi M.B., Schild A.L. \& Sallis E.S.V. 2017. [Tuberculosis in domestic cats (Felis catus) in southern Rio Grande do Sul.] Tuberculose em felinos domésticos no sul do Rio Grande do Sul. Pesquisa Veterinária Brasileira 37(7):725-728. Laboratório Regional de Diagnóstico, Faculdade de Veterinária, Universidade Federal de Pelotas, Campus Universitário s/n, Pelotas, RS 96010-900, Brazil. E-mail: clairton.marcolongo@terra.com.br

Clinical pathological aspects of four cases of tuberculosis in domestic cats in southern Rio Grande do Sul is described. A retrospective study was conducted of cats diagnosed with tuberculosis and necropsied at the Regional Diagnostic Laboratory of the Federal University of Pelotas (LRD/UFPel) from January 2000 to December 2014. In two cases, the amplification of genetic sequence IS6110 specific to Mycobacterium tuberculosis demonstrated that the disease was of human origin. The other two were positive for Mycobacterium spp. The clinical signs were characterized by progressive weight loss, anorexia, and dyspnea. The evident macroscopic changes were cachexia, swelling of submandibular lymph nodes with focal areas of caseous aspect on cut surface. The lungs had multifocal caseous areas at the pleural surface. Histologically, the cats had pneumonia and granulomatous lymphadenitis. The Ziehl-Neelsen staining revealed the presence of alcohol-acid resistant bacteria. There was a positive immunostaining for mycobacteria by immunohistochemistry technique. We alert to the importance of feline tuberculosis as a public health problem, because infected cats may serve as source for dissemination of mycobacteria in the environment, and be sentinels for the occurrence of the disease in humans.
\end{abstract}

INDEX TERMS: Felis catus, cats, pulmonary tuberculosis, Mycobacterium tuberculosis.

RESUMO.- Descrevem-se os aspectos clínico patológicos de quatro casos de tuberculose em felinos domésticos no Sul do Rio Grande do sul. Foi realizado um estudo retrospectivo dos casos diagnosticados como tuberculose em gatos necropsiados no Laboratório Regional de Diagnóstico da Universidade Federal de Pelotas (LRD/UFPel) no período de janeiro de 2000 a dezembro de 2014. Em dois casos a amplificação da sequência genética IS6110 específica para Mycobacterium tuberculosis demonstrou que a doença era de origem humana.

\footnotetext{
${ }^{1}$ Recebido em 13 de maio de 2016.

Aceito para publicação em 10 de outubro de 2016.

${ }^{2}$ Programa de Pós-Graduação em Veterinária, Faculdade de Veterinária (FV), Universidade Federal de Pelotas (UFPel), Campus Universitário s/n, Pelotas, RS 96010-900, Brasil.

${ }^{3}$ Faculdade de Veterinária, Centro Universitário Ritter dos Reis (UniRitter), Rua Orfanotrofio 555, Alto Teresópolis, Porto Alegre, RS 90840-440, Brasil. *Autor para correspondência: clairton.marcolongo@terra.com.br

${ }^{4}$ Laboratório Regional de Diagnóstico, FV-UFPel, Pelotas, RS 96010-900, Brasil.
}

Os outros dois foram positivos para Mycobacterium spp. Os sinais clínicos caracterizaram-se por emagrecimento progressivo, anorexia e dispneia. As alterações macroscópicas evidenciadas eram de caquexia, aumento de volume dos linfonodos submandibulares com áreas focais de aspecto caseoso ao corte. Nos pulmões havia áreas multifocais a coalescentes amareladas de aspecto caseoso, discretamente elevadas e firmes na superfície pleural. Histologicamente havia broncopneumonia e linfadenite granulomatosas. A coloração de Ziehl-Neelsen evidenciou a presença de bacilos álcool-ácidos resistentes. Houve imunomarcação positiva para micobactéria pela técnica de imuno-histoquímica. Alerta-se para a importância da tuberculose felina como um problema de saúde pública pois gatos infectados podem servir de fonte para a disseminação das micobactérias no ambiente, além de serem sentinelas para a ocorrência da enfermidade em seres humanos.

TERMOS DE INDEXAÇÃO: Felis catus, felinos, tuberculose pulmonar, Mycobacterium tuberculosis. 


\section{INTRODUÇÃO}

Tuberculose (TB) é uma enfermidade infecto-contagiosa, granulomatosa, crônica, causada por bactérias aeróbicas álcool-ácido resistentes, pertencente ao gênero Mycobacterium, que afeta várias espécies de animais, incluindo as aves e, também, o homem (Hillier \& Mundell 2008). É um gênero com grande afinidade espécie-específica e com variáveis potenciais patogênicos (Greene \& Gunn-Moore 2006). A doença continua sendo um importante problema de saúde pública, especialmente em países em desenvolvimento, nos quais esta zoonose tem aumentado nos últimos anos, tanto em animais como em seres humanos, principalmente associada a doenças imunossupressoras (Lawn et al. 2002, WHO 2014). Estima-se que cerca de 1,7 bilhões de indivíduos (30\% da população mundial) estejam infectados pelo M. tuberculosis. Nos países desenvolvidos, cerca de 40.000 mortes são devidas à TB e mais de 400.000 casos novos são descobertos a cada ano (WHO 2014).

As micobactérias podem causar doença pulmonar, gastroentérica e/ou disseminada em cães e gatos (Snider et al. 1975), e o diagnóstico da enfermidade nestas espécies é difícil, uma vez que a doença pode se desenvolver sem que os animais apresentem sinais clínicos (Aranaz et al. 1996).

Os objetivos deste trabalho foram descrever os aspectos clínico patológicos de tuberculose em felinos domésticos na região sul do Rio Grande do Sul, estabelecendo sua importância como potencial antropozoonótico para a região.

\section{MATERIAL E MÉTODOS}

Para a identificação dos casos de tuberculose felina foram revisados os protocolos de necropsia do Laboratório Regional de Diagnóstico da Faculdade de Veterinária da Universidade Federal de Pelotas (LRD/UFPel) no período de janeiro de 2000 a dezembro de 2014. Desses protocolos foram resgatados os dados epidemiológicos, o histórico clínico dos animais, bem como as descrições macroscópicas, histopatológicas e os resultados da coloração especial de Ziehl-Neelsen (ZN).

Foram resgatados os blocos de parafina e realizados cortes histológicos de pulmão e linfonodos e submetidos à técnica de imuno-histoquímica pelo método streptavidina-biotina com anticorpo primário anti-Mycobacterium tuberculosis. Os cortes foram desparafinizados e realizado bloqueio da peroxidase endógena com peróxido de hidrogênio 3\% diluído em metanol. A recuperação antigênica foi realizada com protease XIV (Sigma) durante 15 minutos à temperatura ambiente. 0 anticorpo anti-M.tuberculosis foi utilizado na diluição de 1:200, overnight à temperatura de $4^{\circ} \mathrm{C}$ e como cromógeno foi utilizado o DAB. As lâminas foram contra-coradas com hematoxilina de Harris e montadas em entelan.

Amostras de tecidos de pulmão e linfonodos em parafina foram enviados ao Laboratório de Zoonoses Bacterianas da Faculdade de Medicina Veterinária e Zootecnia da Universidade de São Paulo, para realização de reação em cadeia da polimerase (PCR). Para a extração do DNA foi usado o mini kitQiaamp DNA Stool (Qiagen), conforme instruções do fabricante. Após as extrações dos DNAs, as reações de amplificação foram realizadas em um processador de PCR com 35 ciclos de temperatura: 1 minuto, $94^{\circ} \mathrm{C}$; $1 \mathrm{~min}, 65^{\circ} \mathrm{C}$ e $2 \mathrm{~min} 72^{\circ} \mathrm{C}$. O DNA amplificado foi analisado por gel de agarose electroforese.

\section{RESULTADOS}

No LRD/UFPel, foram diagnosticados quatro casos de tuberculose em felinos domésticos, entre janeiro de 2000 e dezembro de 2014. A idade dos felinos variou de um a dois anos. Todos os animais eram sem raça definida. Três eram machos e um era fêmea. Os felinos conviviam com seus proprietários dentro de casa, na cidade de Pelotas, mas tinham acesso as ruas. Os animais afetados apresentaram emagrecimento progressivo, anorexia e dificuldade respiratória, com evolução dos sinais clínicos de aproximadamente quatro meses. Não havia menção sobre castração nos protocolos de necropsia. Os resultados foram disponibilizados aos proprietários logo após o diagnóstico.

Na necropsia, os quatro felinos estavam em mau estado corporal (caquexia) e as mucosas pálidas. Dois animais apresentavam aumento de volume dos linfonodos submandibulares com áreas focais de aspecto caseoso ao corte. Nos pulmões havia áreas multifocais a coalescentes amareladas de aspecto caseoso, discretamente elevadas e firmes na superfície pleural (Fig.1A). Nos demais órgãos não foram observadas alterações.

Histologicamente nos pulmões havia broncopneumonia granulomatosa caracterizada por infiltrado inflamatório composto principalmente por linfócitos, plasmócitos, macrófagos, macrófagos epitelióides (Fig.1B) e raras células gigantes tipo Langhans. Por vezes, verificou-se pequenas áreas com necrose caseosa. Lesões similares foram evidenciadas nos linfonodos submandibulares e mediastínicos. Pela coloração de Ziehl-Neelsen foram evidenciados numerosos bacilos álcool ácido resistentes no citoplasma de macrófagos e macrófagos epitelióides (Fig.2A) e de células gigantes, nos pulmões e nos linfonodos.

Dos quatro casos com diagnóstico de tuberculose, dois tiveram marcação positiva para detecção de micobactéria pela imuno-histoquímica (Fig.2B) e amplificação da sequência genética IS6110 específica do Mycobacterium tuberculosis pela PCR. As demais amostras amplificaram apenas para o gênero Mycobacterium (hsp65).

\section{DISCUSSÃO E CONCLUSÃO}

O diagnóstico de tuberculose nos felinos deste estudo foi baseado nos sinais clínicos, nos achados de necropsia, nas lesões histológicas, na imuno-histoquímica e na amplificação genética de Mycobacterium spp. Apesar de não ter sido amplificado M. tuberculosis em duas amostras, não pode descartar-se essa espécie de Mycobacterium como causa da enfermidade. Outra espécie que causa tuberculose em felinos é o M. bovis, no entanto, os animais eram criados no meio urbano e o consumo de leite in natura, que é a forma mais comum de transmissão da doença para felinos, não é uma prática comum nas cidades. Além disso a conservação das amostras em parafina e/ou formol pode levar a fragmentação do DNA, pelo efeito do fixador, tempo de fixação e temperatura utilizada no processamento do material (Malik et al. 2013) e diminuir a possibilidade de identificação da espécie.

No Brasil há apenas uma descrição de tuberculose pulmonar em gatos domésticos (Firmino et al. 2015), porém 

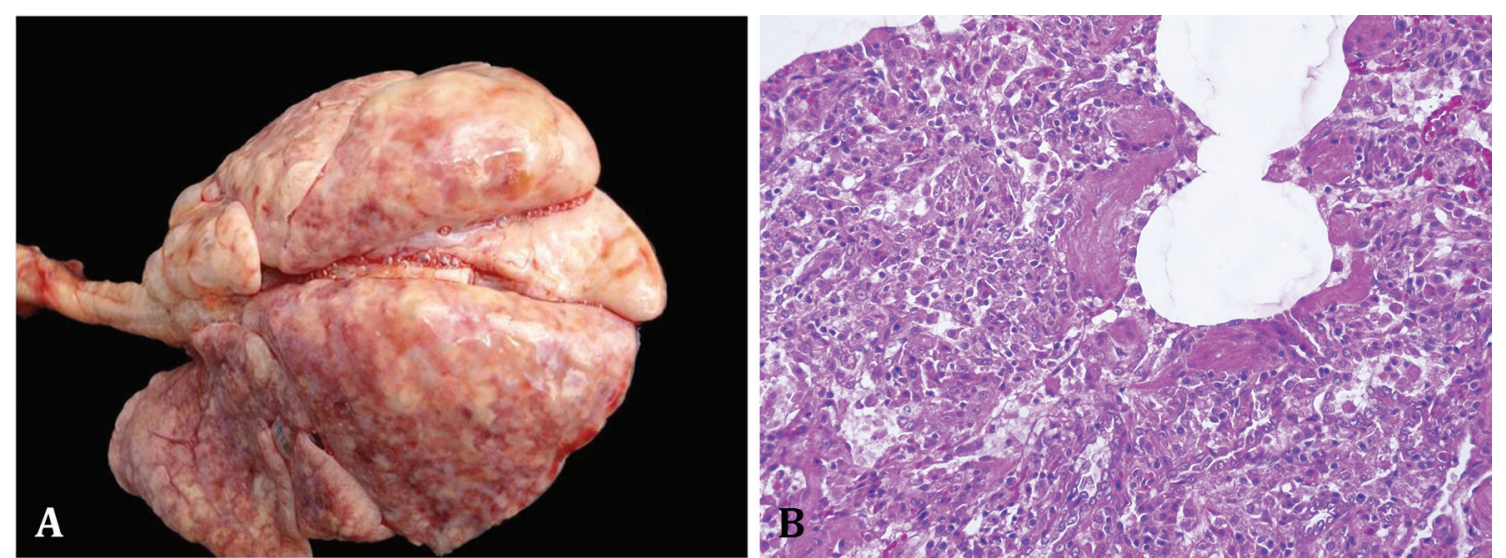

Fig.1. Tuberculose em felinos domésticos. (A) Pulmão com áreas multifocais a coalescentes amareladas, discretamente elevadas na superfície pleural. (B) Pneumonia intersticial com infiltrado de macrófagos, macrófagos epitelióides, plasmócitos e linfócitos. HE, obj.20x.
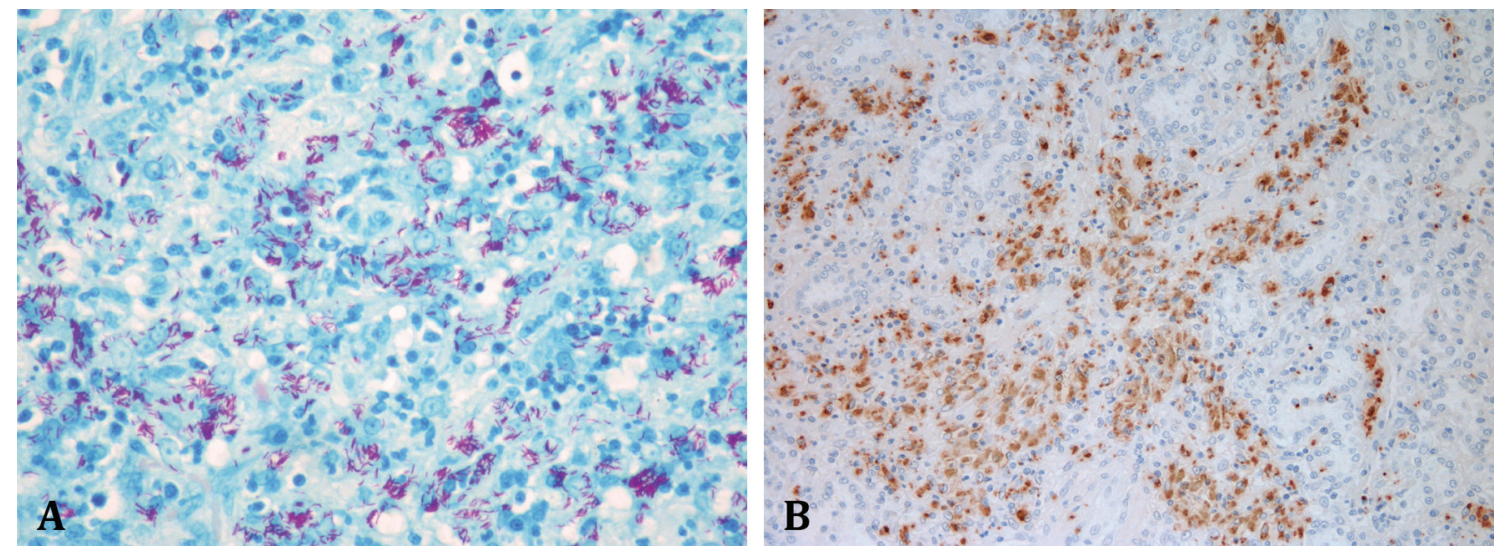

Fig.2. Tuberculose em felinos domésticos. (A) Pulmão com inúmeros bacilos álcool ácido resistentes no citoplasma de macrófagos e macrófagos epitelióides. Ziehl-Neelsen, obj.40x. (B) Imunomarcação positiva para Mycobacterium tuberculosis em macrófagos e macrófagos epitelióides. Método estreptavidina ligada à peroxidase, cromógeno DAB, obj.40x.

sem a identificação do agente causador da enfermidade. Geralmente os casos relatados no país referem-se à micobacteriose cutânea (Larsson et al. 2006, Silva et al. 2010). No RS, assim como nos outros Estados Brasileiros, TB pulmonar tem sido diagnosticada preferencialmente em bovinos leiteiros, sendo causada pelo M. bovis, com dados de prevalência somente nessa espécie (Poletto et al. 2004, Riet-Correa \& Garcia 2007). TB foi mencionada em felinos, sendo causada pelo $M$. bovis através da ingestão de leite de vaca contaminado ou de carne, ou até mesmo pelo contato com bovinos ou roedores infectados, principalmente naquelas regiões com alta prevalência de TB em bovinos (Blunden \& Smith 1996, Gibbens 2014, Gunn-Moore 2014). Nos casos aqui observados, não havia menção do tipo de alimentação que os felinos recebiam, porém, os animais conviviam com seus proprietários e tinham acesso as ruas da cidade, onde o convívio com outros felinos, roedores é muito estreito o que pode ter facilitado a contaminação dos gatos (contaminação trans-espécies). Chama a atenção que as infecções caninas e felinas por $M$. tuberculosis são consideradas como antropozoonose, ou seja, a transmissão ocorre dos seres humanos para os animais (Love \& Jones 2012).

Os casos de TB em felinos domésticos deste estudo ocorreram mais em machos que em fêmeas, tal como ocor- reu em um outro estudo sobre a enfermidade em felinos na Inglaterra (Gunn-Moore 2014). Provavelmente esses gatos estão sob o maior risco de infecção devido ao hábito de caça e de briga com outros gatos.

No presente estudo os felinos apresentaram sinais clínicos caracterizados por dispneia e emagrecimento progressivo com evolução de dois a quatro meses. Os sinais clínicos da tuberculose em felinos, quando presentes, podem variar, dependendo do Mycobacterium que invade o organismo e do órgão afetado (Greene \& Gunn-Moore 2006). Geralmente, quando há comprometimento pulmonar observa-se dispneia e tosse leve (Love \& Jones 2012).

As lesões macroscópicas e microscópicas observadas eram lesões típicas de tuberculose pulmonar. Lesões semelhantes foram, também, descritas em outros estudos de TB em felinos na Inglaterra, na Espanha, na Grã-Bretanha e na Nova Zelândia (Aranaz et al. 1996, Gunn-Moore 2014). A coloração de ZN e a imuno-histoquímica demonstraram ser boas técnicas para auxiliar no diagnóstico diferencial da enfermidade. A presença de bacilos álcool-ácido resistentes na coloração de ZN é indicativa da doença (Gunn-Moore et al. 1996).

A tuberculose felina deve ser incluída no diagnóstico diferencial de outras doenças de gatos domésticos que cur- 
sam com emagrecimento progressivo e tosse, bem como, enfermidades pulmonares com lesões granulomatosas, como micose sistêmica, diferenciada pela presença de hifas/leveduras fúngicas na lesão histológica, nocardiose, que no presente caso foi diferenciada pela imuno-histoquímica e neoplasias.

Chama-se a atenção para a importância da tuberculose felina como um problema de saúde pública, especialmente pela causada pelo $M$. tuberculosis pois gatos infectados podem servir de fonte para a disseminação das bactérias no ambiente, e consequentemente para o homem e para outros animais domésticos.

Atualmente o convívio do homem com seus animais de estimação é muito estreito o que favorece a disseminação de zoonoses. A ocorrência de tuberculose em felinos indica a presença do agente no ambiente, demonstrando a necessidade de investigação da provável ocorrência da doença nas pessoas e/ou animais de convivência próxima.

\section{REFERÊNCIAS}

Aranaz A., Liébana E., Pickering X., Novoa C., Mateos A. \& Domínguez L. 1996. Use of polymerase chain reaction in the diagnosis of tuberculosis in cats and dogs. Vet. Rec. 138:276-280.

Blunden A.S. \& Smith K.C. 1996. A pathological study of a mycobacterial infection in a cat caused by a variant with cultural characteristics between Mycobacterium tuberculosis and M. bovis. Vet. Rec. 138:87-88.

Firmino M.O., Frade M.T.S., Ferreira J.S. \& Dantas A.F.M. 2015. Tuberculose em gato doméstico. Anais III Congresso Brasileiro de Patologia Veterinária, Enapave 2015. 238p.

Gibbens N. 2014. Mycobacterium bovis infection in cats. Vet. Rec. 174:331332.

Greene C.E. \& Gunn-Moore D.A. 2006. Mycobacterial infections, p.462-477. In: Greene C.E. (Ed.), Infectious Diseases of the Dog and Cat. 3rd ed. W.B. Saunders, Philadelphia.
Gunn-Moore D.A., Jenkins P.A. \& Lucke V.M. 1996. Feline tuberculosis: a literature review and discussion of 19 cases caused by an unusual mycobacterial variant. Vet. Rec. 138:53-58.

Gunn-Moore D. 2014. Feline tuberculosis caused by Mycobacterium bovis. Veterinary Record. 174:322-323.

Hillier A. \& Mundell A.C. 2008. Micobacteriose, p.435-440 In: Birchard S.J., \& Sherding R.G. (Eds), Manual Saunders: clínica de pequenos animais. $3^{a}$ ed. Roca, São Paulo.

Larsson C.E., Delayte E.H., Balda A.C., Michalany N.S., Pinheiro S.R., Otsuka M. \& Roxo E. 2006. Dermatite micobacteriana atípica em gato: relato de caso. Arq. Bras. Med. Vet. Zootec. 58(6):1092-1098.

Lawn S.D., Butera S.T. \& Shinnick T.M. 2002. Tuberculosis unleashed: the impact of human immunodeficiency virus infection on the host granulomatous response to Mycobacterium tuberculosis. Microb. Infect. 4:635646.

Love B.C. \& Jones R.L. 2012. Mycoplasmal and bacterial diseases, p.495521. In: Greene E.C. (Ed.), Infectious Diseases of the Dog and Cat. 4th ed. Saunders Elsevier, St Louis.

Malik R., Bronwyn S., Reppas G. Lapries C., O’Brien C. \& Fyfe J. 2013. Ulcerated and nonulcerated nontuberculous cutaneous mycobacterial granulomas in cats and dogs. Vet. Dermatol., Oxford, 24(1):146-e33.

Poletto R., Kreutz L.C., Gonzales J.C. \& Barcellos L.J.G. 2004. Prevalência de tuberculose, brucelose e infecções víricas em bovinos leiteiros do município de Passo Fundo, RS. Ciência Rural 34(2):595-598.

Riet-Correa F. \& Garcia M. 2007. Tuberculose, p.432-442. In: Riet-Correa F., Schild A.L., Lemos R.A.A. \& Borges J.R.J. (Eds), Doenças de Ruminantes e Eqüídeos. Vol.1. 3ª ed. Pallotti, Santa Maria.

Silva D.A., Gremião I.D.F., Menzes R.C., Pereira S.A., Figueiredo F.B., Ferreira R.M.C. \& Pacheco T.M.V. 2010. Micobacteriose cutânea atípica felina autóctone no município do Rio de Janeiro, Brasil. Acta Scient. Vet. 38(3):327-331.

Snider W.R., Cohen D., Reif J.S., Stein S.C. \& Prier J.E. 1975. Tuberculin sensitivity in a high-risk canine population. Am. J. Epidemiol. 102(2):185190.

WHO 2014. Informe mundial sobre la tuberculosis. Disponível em $<$ http://www.who.int/tb/publications/global_report/es/> Acesso em 6 nov. 2015. 